\title{
The intertidal zoning of cockles (Cerastoderma edule) in the Wadden Sea, or why cockle fishery disturbed areas of relatively high biodiversity
}

\author{
Jan Jacobus Beukema $\cdot$ R. Dekker
}

Received: 12 August 2008 / Revised: 17 March 2009 / Accepted: 18 March 2009 / Published online: 8 April 2009

(C) Springer-Verlag and AWI 2009

\begin{abstract}
Recently, Kraan et al. (ICES J Mar Sci 64:1735-1742, 2007) reported that areas in the Wadden Sea selected by mechanical cockle dredgers were of greater zoobenthic diversity than areas that remained undredged. The present paper attempts to explain this observation, focussing on the elevation-related zoning of the macrobenthic fauna on tidal flats. Dense beds of cockles Cerastoderma edule occur in a specific intermediate intertidal-height zone where more species are present (and reach their maximal abundance) than in either lower or higher zones. This coincidence of preferred intertidal zones in many species, including cockles, may cause the higher species richness (and higher total macrozoobenthic biomass) of the fisherchosen dredging areas as compared to other nearby nondredged tidal-flat areas.
\end{abstract}

Keywords Biodiversity - Cockle dredging ·

Site selection $\cdot$ Tidal flats $\cdot$ Wadden Sea

\section{Introduction}

The impact of a fishery should not be judged only from the extent of the affected area: quality aspects of the disturbed area should be taken into account as well, such as its sensitivity to fishing pressure (Hiddink et al. 2007) and various other aspects of its quality. Criteria for quality of an area

Communicated by H.-D. Franke.

J. J. Beukema $(\bowtie) \cdot$ R. Dekker

NIOZ Royal Netherlands Institute for Sea Research,

P.O. Box 59, 1790 AB Den Burg, Texel, The Netherlands

e-mail: jan.beukema@nioz.nl could include a/o its biological diversity (quantified by, e.g., species richness), productivity, and biomass of other species. Sometimes, little difference is found in composition, structure and biomass of species assemblages in areas subjected to fishing and exclusion areas (Schejter et al. 2008). However, in the case of mechanical dredging for cockles Cerastoderma edule (L.) in the Dutch Wadden Sea, Kraan et al. (2007) show that the tidal-flat areas that were selected by fishers happened to be richer in macrozoobenthic species than surrounding non-fished areas. As a consequence, disturbances by mechanical cockle fishery (Piersma et al. 2001; Ens et al. 2004) stroke areas of relatively high biodiversity. In all four dredging events covered in their study, Kraan et al. (2007) found such differences in species richness, amounting to $\sim 25 \%$.

Their study shows convincingly that cockle fishers dredged for cockles in relatively species-rich areas, but they do not explain how this coincidence was accomplished. Before fishing (which is done at high tide), cockle fishers inspect tidal flats by foot at low tide, searching for plots of high cockle density, preferably several hundreds of adult cockles $\mathrm{m}^{-2}$. Mechanical fishery is profitable only at densities of $>\sim 50 \mathrm{~m}^{-2}$ of cockles of $>22-\mathrm{mm}$ shell length, as smaller cockles escape from the suction dredges used (Kamermans and Smaal 2002). It is improbable that they would be able to directly select areas on the basis of species richness. We hypothesize that their selection for areas with high cockle abundance inevitably leads to a concentration of fishery disturbance in areas characterized by a high biodiversity. Patterns of species richness on tidal flats may arise from place-to-place variation in a number of environmental variables, such as sediment composition and intertidal height. We have chosen to study the relationships between intertidal heights and cockle abundance as well as species richness, using data from a long-term multi-station 
series of observations on Balgzand to test the above hypothesis.

\section{Methods}

We use results of a 38-year (started around 1970) sampling program along 12 transects on Balgzand, a $50-\mathrm{km}^{2}$ tidal-flat area in the westernmost part of the Wadden Sea (Beukema 1988; Beukema and Cadée 1997). These transects covered an intertidal height range of -10 to $+6 \mathrm{dm}$, thus including the entire intertidal range of heights (of on average $\sim-8 \mathrm{dm}$ to $\sim+6 \mathrm{dm}$ compared to mean-tide level) and all common sediment types from almost siltfree sand to soft mud with a silt content of $\sim 20 \%$ (compare Fig. 2 of Beukema 1988). Each transect had a length of $1 \mathrm{~km}$ and at every $20 \mathrm{~m}$ samples of 1.9 (in late winter) or 0.9 (in late summer) $\mathrm{dm}^{2}$ each were taken twice annually. These individual samples were assembled per $100 \mathrm{~m}$; thus, for each transect and each sampling occasion, 10 counts representing (in winter) 0.095 or (in summer) $0.045 \mathrm{~m}^{2}$ each are available of all species present that were retained by a $1-\mathrm{mm}$ sieve. This program yielded on Balgzand $38 \times 12 \times 10=\sim 4,500$ separate estimates for each of the two seasons (some data sets are limited to $\sim 3,500$ estimates, as late-summer samples were incomplete for some species before 1980). Because cockles were fished in late summer, we used the late-summer estimates to study distribution patterns of species richness, adult cockles and some other species. The larger samples of the late-winter samplings were used to study overall relationships between cockle biomass and biomass and species numbers of other species. Data on intertidal height of the $12 \times 10$ sampling sites were read from sounding charts kindly made available by the Rijkswaterstaat (Dutch Ministry of Transport, Public Works and Water Management). Because, at most sites, these heights hardly changed during the period of observation, we used longterm mean heights.

\section{Results}

Zoning of tidal-flat zoobenthos

Like other tidal flat areas (Dittmann 2000), the Wadden Sea tidal flats show a clear zoning of the macrozoobenthic fauna that is related to intertidal height (Dankers and Beukema 1983; Armonies and Hellwig-Armonies 1987; Beukema 1988; Beukema and Flach 1995; Beukema and Cadée 1997; Beukema 2002, and literature therein). For Balgzand, this zoning is depicted in Fig. 4 of Beukema (2002); for the entire Dutch and German Wadden Sea in
Figs. 8 and 9 of Dankers and Beukema (1983). In short, near the salt marshes around the high-tide level (HTL) the number of macrozoobenthic species is low (compare Fig. 1b) and these few species are characterized by low individual body weights. Despite their often high numerical abundance, biomass values are low at high tidal flats. With increasing distance from the coast and declining intertidal height, the number of species increases as does their mean body weight, resulting in rapidly increasing biomass values. These increases continue till maximal values are reached at a height somewhere between mean-tide level (MTL) and low-tide level (LTL). At still lower heights, approaching LTL, values of species number, numerical abundance, mean body weight and total biomass decline to the relatively low values observed at the edges of the subtidal.

\section{Zoning of cockles}

The summer distribution of fishable cockles as observed on Balgzand (Fig. 1a) was similar to the pattern for the entire Dutch Wadden Sea as shown in Fig. 40 of Ens et al. (2004): bell-shaped with maximal values at heights somewhere between MTL and LTL. The values of the standard errors (indicated only for the upper graph of Fig. 1a) relative to the magnitudes of the differences between the percentages clearly indicate that the presence of cockles in high densities occurred significantly more frequently at intermediate heights than at either high or low intertidal heights. A similar bell-shaped relationship between intertidal height (emersion time) and cockle biomass was found in tidal flat areas in the Eastern Scheldt, in the southwest of The Netherlands (Kater et al. 2006).

\section{Zoning of species richness and biomass}

Note that the above relationship between intertidal height and cockle bed occurrence (Fig. 1a) is basically similar to the one between height and species richness (Fig. 1b). The latter type of relationship is not limited to Balgzand, as similarly-shaped relationships are shown for the entire Dutch and German Wadden Sea in Fig. 9 of Dankers and Beukema (1983). Similarly, bell-shaped relationships for samples taken in late winter in three different decades on Balgzand are shown in Fig. 3b of Beukema (2002), pointing out that the shapes of these curves do not depend on season nor on period of observation. Not only zoobenthic species richness, also total zoobenthic biomass shows a bell-shaped relationship with intertidal height in all investigated parts of the Wadden Sea, see Fig. 8 of Dankers and Beukema (1983) and Fig. 6 of Beukema (2002). Again, maximal values are invariably observed at heights somewhere between MTL and LTL. 

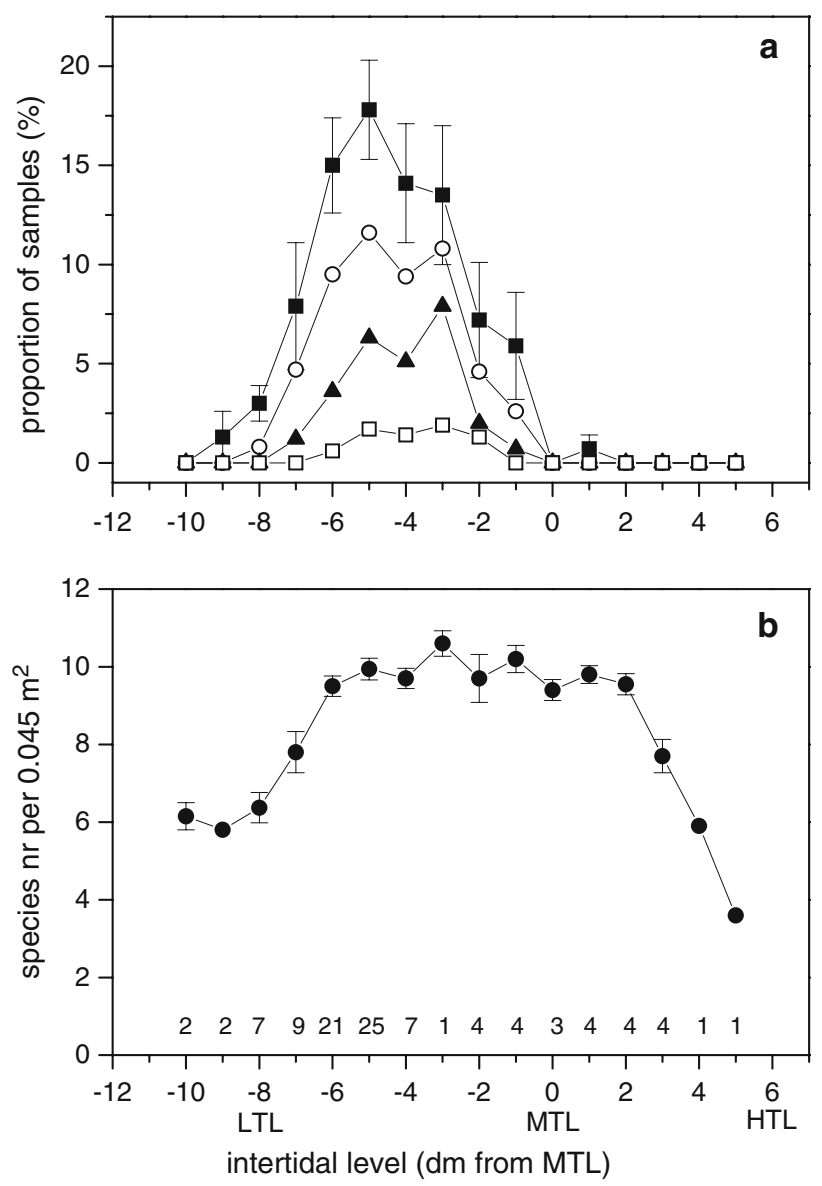

Fig. 1 Relationships between intertidal height (in dm from MTL) and a the proportion (in \%) of the samples taken at that level revealing a certain high numerical density of large (shell length $>22 \mathrm{~mm}$ ) cockles, and $\mathbf{b}$ species richness of macrozoobenthos (in number of species per $0.045 \mathrm{~m}^{2}$ ). Data of late-summer sampling of $100-\mathrm{m}$ sections of 12 transects of $1 \mathrm{~km}$ each on Balgzand. Levels of mean low tide (LTL), mean tide (MTL) and mean high tide (HTL) indicated. Numbers of 100-m sections at each height indicated along horizontal axis of lower graph. a Data of entire 38-year (1970-2007) period of observation, showing relationships for different cockle densities: (solid squares) $>50 \mathrm{~m}^{-2}$ (open circles) $>100 \mathrm{~m}^{-2}$, (solid triangles) $>200 \mathrm{~m}^{-2}$, and (open squares) $>500 \mathrm{~m}^{-2}$. Standard errors shown only for values of upper line $\left(>50\right.$ large cockles $\mathrm{m}^{-2}$ ). b Averages (with $1 \mathrm{SE}$ ) of the 28-year (1980-2007) section-mean numbers of macrozoobenthic species found (for example: 3 sections were located at MTL with 28 observation each and the pictured point of 9.4 was the average of three 28-year means)

\section{Cockle-zoobenthos relationships}

As a consequence of the above described similarities in intertidal height-related distribution patterns of cockles and some characteristics of total macrozoobenthos (i.e., its species richness and total biomass), positive relationships are bound to arise between cockle abundance and species richness (Fig. 2a, b) and between cockle biomass and total zoobenthic biomass (Fig. 2c). All three relationships shown in Fig. 2 were significantly positive (see
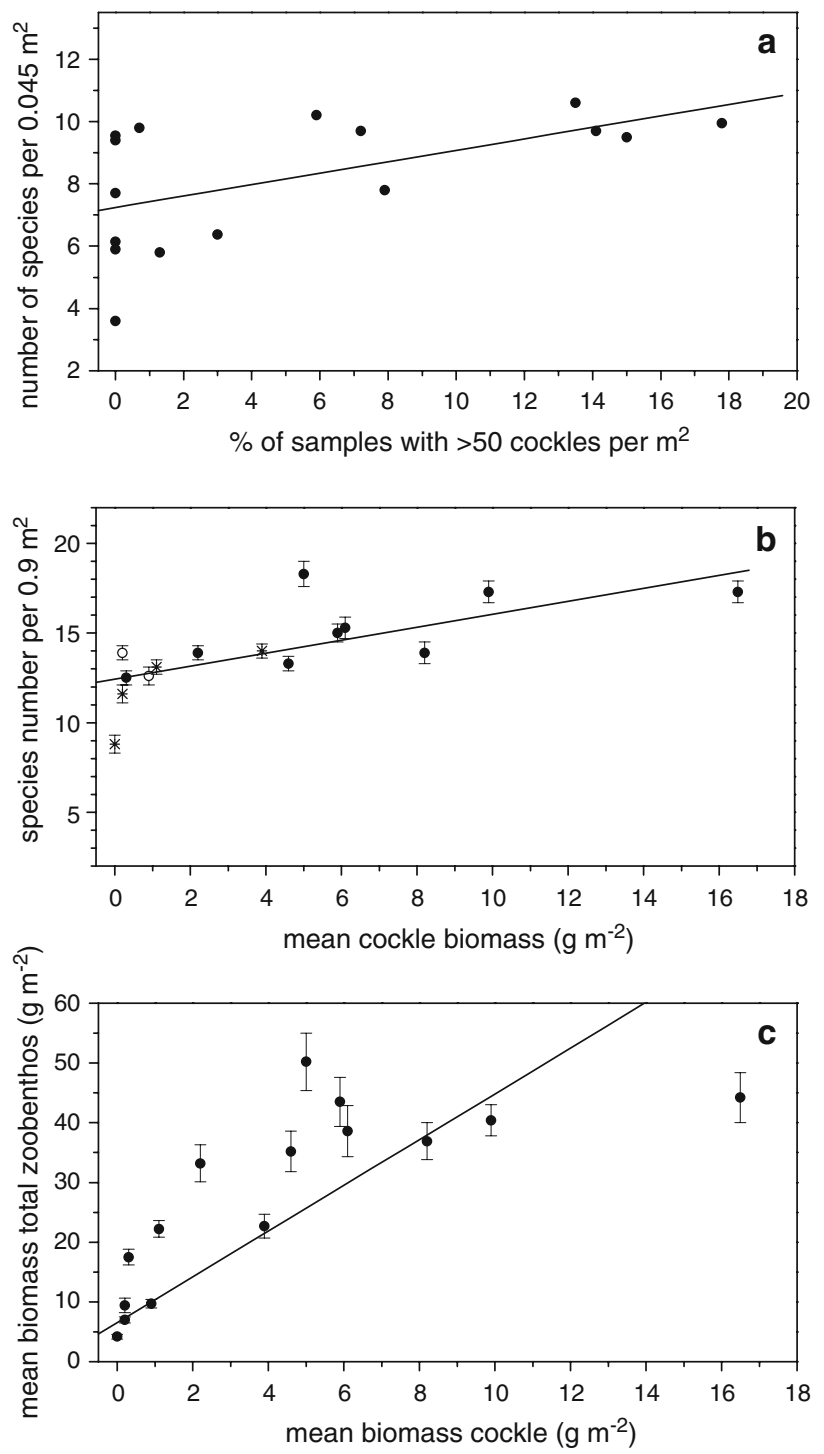

Fig. 2 Relationships between local long-term means of cockle abundance and $(\mathbf{a}, \mathbf{b})$ mean number of macrozoobenthic species and (c) mean biomass of total macrozoobenthos (in $\mathrm{g} \mathrm{AFDM} \mathrm{m}{ }^{-2}$ ). All data shown are long-term means of 15 sampling sites (12 transects of $1 \mathrm{~km}$ each and 3 squares of $900 \mathrm{~m}^{2}$ each) on Balgzand. a Data of late-summer samplings, as shown in Fig. 1. The straight line shows the best linear fit: species number $=7.2+0.18$ percentage of samples with cockle densities of $>50 \mathrm{~m}^{-2}(n=16, r=0.57, P=0.02)$. Standard errors are shown in Fig. 1. b, $\mathbf{c}$ Data of 30 late-winter samplings (the 30 years of the 1970-1999 period). Cockle abundance expressed as long-term mean biomass at the 15 transects or squares, in $\mathrm{g}$ AFDM m $\mathrm{m}^{-2}$. The location of the 15 sampling sites is indicated in $\mathbf{b}$ : high near-shore sites (above MTL) by a star, low off-shore sites (around low-tide level) by an open circle, and between these extreme levels by solid circles. The straight lines show the best linear fits: $\mathbf{b}$ species number $=12.4+0.38$ cockle biomass $(n=15, \quad r=0.72, P=0.002) \quad \mathbf{c}$ total biomass $=$ $6.5+3.8$ cockle biomass $(n=15, r=0.83, P=0.0001)$

legends). Thus, both in late summer (Fig. 2a) as well as in late winter (Fig. 2b) were species numbers per unit area higher at sampling sites with high than with low cockle abundance. Low values occurred particularly at the 
highest and lowest intertidal heights (see star-shaped and open points in Fig. 2b).

In Fig. 2c, the values shown of total zoobenthic biomass include cockle biomass and this will bias the pictured relationship. However, if the lower values of total biomass minus cockle biomass were plotted on the vertical axis, the relationship with cockle biomass remained significantly positive: $r=0.57, n=15, P=0.03$.

\section{Examples of special distribution patterns}

Many species that live on tidal flats of the Wadden Sea show their maximal abundance at intermediate height levels between MTL and LTL, but in some species maximal numbers and biomass are found at extreme intertidal heights (Beukema and Cadée 1997). Usually, the latter are relatively small-bodied species such as (in the low intertidal) the bivalve Tellina tenuis and (in the high intertidal) the gastropod Hydrobia ulvae, the crustacean Corophium volutator, and the bivalve Abra tenuis. Distribution patterns in relation to intertidal height of the two above mentioned bivalve species are shown in Fig. 3. Note the near-absence and very low mean numerical densities of these two species at the intermediate intertidal levels, where cockles show their maximal abundance (Fig. 1a) and species richness is maximal (Fig. 1b).

\section{Discussion}

The above analysis of Balgzand data corroborates the conclusion drawn by Kraan et al. (2007), who gathered their data in a different part of the Wadden Sea. Both studies show that areas with high cockle densities (and therefore attractive to cockle dredgers) are characterized by relatively high numbers of zoobenthos species. The present study adds that cockle-rich areas also showed high values of total macrozoobenthic biomass (Fig. 2c) and biomass of all zoobenthic species minus cockles. On Balgzand, the areas with most cockles showed species numbers of roughly $40 \%$ above those of cockle-poor areas (Fig. 2a, 2b) and biomass values that were elevated even more (Fig. 2c).

Kraan et al. (2007) list in their Table 1 several species that occurred with a significantly higher frequency in areas that were selected by cockle fishers than in areas that remained undredged. Some species, however, occurred less frequently in fisher-selected areas, though only one (Tellina tenuis) significantly so. This is exactly the one species among their listed species with a maximal occurrence at the lowest intertidal levels (Fig. 3a). The two other species of their list that occurred more than twice as often in nondredged than in fisher-selected areas are Abra tenuis and Corophium volutator. These species again show a special
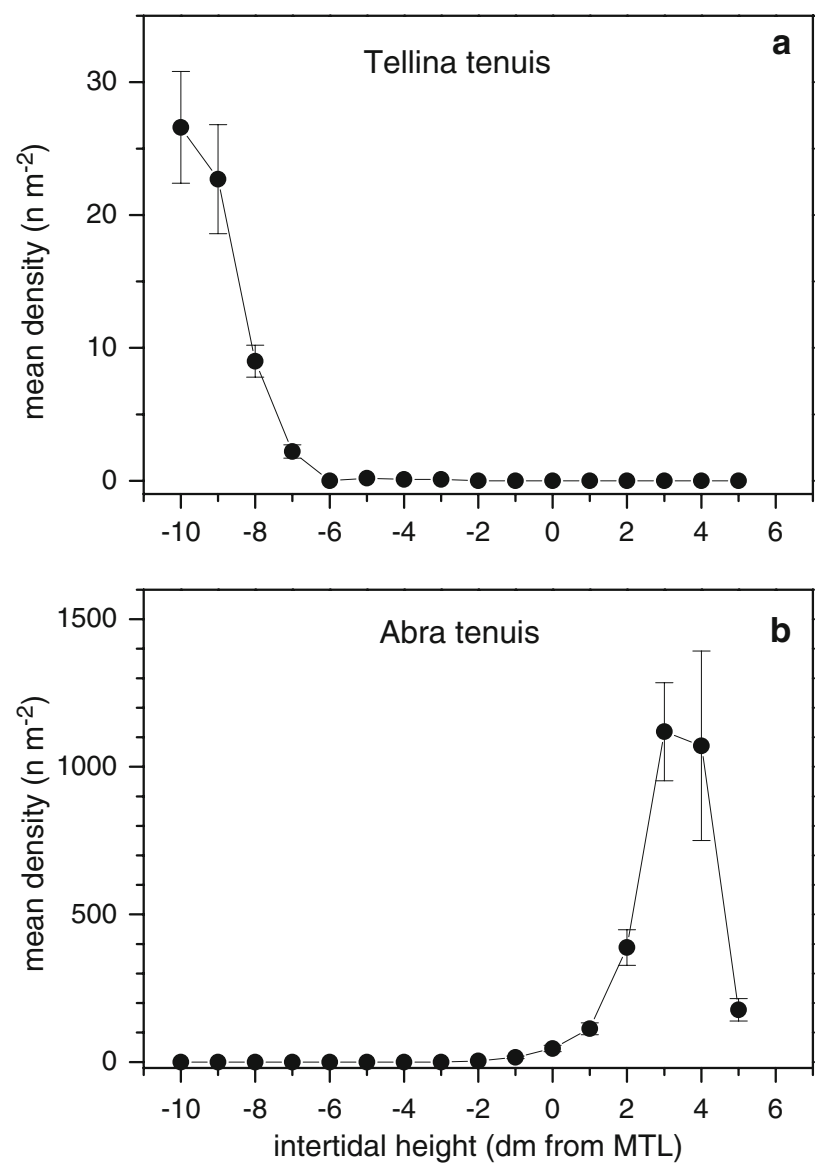

Fig. 3 Examples of relationships between intertidal height (in $\mathrm{dm}$ from MTL) and mean abundance (in $\mathrm{n} \mathrm{m}^{-2}$ with $1 \mathrm{SE}$ ) for two bivalve species that are most abundant at extreme intertidal levels: a Tellina tenuis and $\mathbf{b}$ Abra tenuis. Data of late-summer sampling in 35 years (1973-2007) of 100-m sections of 12 transects of $1 \mathrm{~km}$ each on Balgzand. Numbers of sampled sections at each height as indicated in Fig. $1 \mathrm{~b}$; the numbers of observations are 35 times these numbers. The standard errors reflect the large between-year variability in $\mathrm{n} \mathrm{m}^{-2}$

distribution pattern, in these cases with maximal abundance very high in the intertidal (see Fig. $3 b$ for A. tenuis and Fig. 3 of Beukema and Flach 1995 for $C$. volutator). The special position of the above three species in the order of species of relative occurrence in fisher-selected versus nondredged areas point to differences in height-frequency distribution of the two groups of sites sampled by Kraan et al. (2007), viz., a relatively larger proportion of sampling sites at extreme intertidal heights (either very high or very low) within the non-dredged as compared to the fisher-selected areas.

Unfortunately, Kraan et al. (2007) do not provide any actual data on heights of their sampling sites, but they suggest that the heights were similar in these two areas. However, the geographic distribution of the areas shown in their Fig. 2 clearly indicates that the control (non-dredged) areas usually surrounded the to-be-dredged areas. The latter were 
generally somewhere in the central part of extensive tidal flats. Areas surrounding such central areas are on average closer to the boundaries of the total area, and these boundaries include coasts as well as tidal streams. Logically, if control areas are chosen in this way, they would include a higher proportion of both very high (near the coasts) as well as very low (near the subtidal of tidal streams) tidal flats than the to-be-dredged areas. More detailed unpublished information corroborates this view: though the mean heights were not significantly different between the two data sets, the variances were (personal communication C. Kraan, 27th January 2009). This means that the nondredged control areas indeed showed wider ranges of intertidal heights with higher proportions of sampling sites that were located either very high or very low in the intertidal. This explains (1) the higher numerical densities in nondredged areas of the three above mentioned species with maximal abundance at extreme height levels (as shown in Fig. 3) and (2) the lower biodiversity Kraan et al. (2007) found in their control areas as compared to the cocklefishery areas.

Therefore, we conclude that the observation by Kraan et al. (2007) of higher species numbers in fisher-selected than in other areas was based on a similar underlying zoning of the macrozoobenthic fauna as observed on Balgzand, i.e., the similarly-shaped relationships with intertidal heights of cockle abundance (Fig. 1a) and of species richness (Fig. 1b).

Acknowledgments This study is part of a long-term monitoring programme on macrozoobenthos in the Wadden Sea executed by NIOZ and financially supported by the Dutch Ministry of Transport, Public Works and Water Management.

\section{References}

Armonies W, Hellwig-Armonies M (1987) Synoptic patterns of meiofaunal and macrofaunal abundances and specific composition in litoral sediments. Helgol Meeresunters 41:83-111
Beukema JJ (1988) An evaluation of the ABC-method (abundance/ biomass comparison) as applied to macrozoobenthic communities living on tidal flats in the Dutch Wadden Sea. Mar Biol 99:425433

Beukema JJ (2002) Expected changes in the benthic fauna of Wadden Sea tidal flats as a result of sea-level rise or bottom subsidence. J Sea Res 47:25-39

Beukema JJ, Cadée GC (1997) Local differences on macrozoobenthic response to enhanced food supply caused by mild eutrophication in a Wadden Sea area: food is only locally a limiting factor. Limnol Oceanogr 42:1424-1435

Beukema JJ, Flach EC (1995) Factors controlling the upper and lower limits of the intertidal distribution of two Corophium species in the Wadden Sea. Mar Ecol Prog Ser 125:117-126

Dankers N, Beukema JJ (1983) Distributional patterns of macrozoobenthic species in relation to some environmental factors. In: Wolff WJ (ed) Ecology of the Wadden Sea, vol 1. Balkema, Rotterdam, pp 69-103

Dittmann S (2000) Zonation of benthic communities in a tropical tidal flat of north-east Australia. J Sea Res 43:33-51

Ens BJ, Smaal AC, De Vlas J (2004) The effects of shellfish fishery on the ecosystem of the Dutch Wadden Sea and Oosterschelde. Alterra-rapport 1011, Alterra, Wageningen, pp 212

Hiddink JG, Jennings S, Kaiser MJ (2007) Assessing and predicting the relative ecological impacts of disturbance on habitats with different sensitivities. J Appl Ecol 44:405-413

Kamermans P, Smaal AC (2002) Mussel culture and cockle fisheries in The Netherlands: finding a balance between economy and ecology. J Shellfish Res 21:509-517

Kater BJ, Geurts van Kessel AJM, Baars JJMD (2006) Distribution of cockles Cerastoderma edule in the Eastern Scheldt: habitat mapping with abiotic variables. Mar Ecol Prog Ser 318:221-227

Kraan C, Piersma T, Dekinga A, Koolhaas A, Van der Meer J (2007) Dredging for edible cockles (Cerastoderma edule) on intertidal flats: short-term consequences of fisher patch-choice decisions for target and non-target benthic fauna. ICES J Mar Sci 64:17351742

Piersma T, Koolhaas A, Dekinga A, Beukema JJ, Dekker R, Essink K (2001) Long-term indirect effects of mechanical cockle-dredging on intertidal bivalve stocks in the Wadden Sea. J Appl Ecol 38:976-990

Schejter L, Bremec CS, Hernandez D (2008) Comparison between disturbed and undisturbed areas of the Patagonian scallop (Zygochlamys patagonica) fishing ground "Reclutas" in the Argentine Sea. J Sea Res 60:193-200 